\title{
Monitoring deformations of Istanbul metro line stations through Sentinel-1 and levelling observations
}

\author{
Kerem Halicioglu' ${ }^{1}$ (D) Esra Erten ${ }^{2,3} \cdot$ Cristian Rossi $^{4}$
}

Received: 1 April 2020 / Accepted: 13 April 2021 / Published online: 29 April 2021

(c) The Author(s) 2021

\begin{abstract}
Turkey, as a developing country, is designing and performing massive construction projects around Istanbul. Beginning from the 1960s, rapid urbanization has been taking place due to industrialization, which brings an increase in the population. Yet, construction projects have been accelerated especially during the last decade, and many new projects are scheduled to be completed in a short time. Ground-based observations are generally carried out to monitor the deformations within construction sites, especially through geometric levelling, and GNSS techniques. However, in most cases, these monitoring measurements are only scheduled within the period of the construction process, and ensuing deformations are usually not considered. In addition to these techniques, the space-based interferometric technique can also be used to define the line of sight surface displacements with high accuracy, using the phase difference between image result for synthetic aperture radar images. In particular, Persistent Scatter Interferometry is one of the interferometric methods that are capable of defining the two-dimensional (vertical and horizontal) deformation for the desired epoch with a high temporal resolution. Thus it can be used as a complementary method for monitoring ground deformations, where the measurement is made by ground-based observations. In this study, the deforming areas related to underground metro construction are investigated through significant displacements between 2015 and 2018 of Sentinel-1 space-borne SAR data using the PSI technique. These results are validated by comparison with available levelling data corresponding to the new metro line.
\end{abstract}

Keywords Surface deformation monitoring $\cdot$ Sentinel-1 $\cdot$ Levelling $\cdot$ Persistent scatter interferometry

\section{Introduction}

Urbanization projects have been increasing due to the governmental policies in Turkey since the 1960s. As a result of the industrialization, and decrease in the agricultural

Kerem Halicioglu

kerem.halicioglu@fu-berlin.de

Esra Erten

eerten@itu.edu.tr

Cristian Rossi

Cristian.Rossi@sa.catapult.org.uk

1 Department of Mathematics and Computer Science, Freie Universität Berlin, Arnimallee, 6, 14195 Berlin, Germany

2 Faculty of Science, Technology, Engineering and Mathematics, The Open University, Harwell, UK

3 Department of Geomatics Engineering, Istanbul Technical University, Istanbul, Turkey

4 Satellite Applications Catapult, Harwell, United Kingdom subventions, rural migration took place towards cities like Istanbul. The migration causes high populated cities, which yields a rapid urbanization process to lodge newcomers (Yapıc1 2019). Istanbul which was responsible for the absorption of the $25 \%$ of the new urban population in Turkey until the 1980s, suffered the most during the urbanization process (Keyder 2010). The trend in population increase continued until the 2000s, and this forced "megaprojects" to take place in city centers (Sonmez 2017). Bearing these factors in mind, the city of Istanbul to become a construction site and a subject of the huge projects, such as KanalIstanbul (Dogan and Stupar 2017), Istanbul Great Airport (PMISPA 2019), and metro lines (IBB 2015). Unfortunately, there have been a few construction-related collapses that led to several causalities (Mimarist 2018; HurriyetDailynews 2017). Therefore, it is vital to perform subsidence monitoring for the city of Istanbul.

The ground-based monitoring activities, such as levelling observations, have been performed during the construction process. On the other hand, the European Space Agency's 
(ESA) Sentinel-1 data set is freely available since 2014, which provides an in-depth analysis of land deformations in urban areas. Using the products of Sentinel mission coupled with the Interferometric Synthetic Aperture Radar (InSAR) technique, it is possible to monitor urban areas in various scales. The InSAR is a very powerful technique to detect Earth surface deformation due to the earthquakes, volcanic unrest, groundwater detection, anthropogenic activity, the motion of glaciers, and asset monitoring (Erten et al. 2010; Dirscherl and Rossi 2018; Øverli Eriksen et al. 2017; Imamoglu et al. 2019; Erten 2013; Tomás et al. 2014; Selvakumaran et al. 2018).

There are current studies regarding surface displacements in selected areas of Istanbul focusing on crustal deformation (Aslan et al. 2018), especially for the European part of Istanbul, discussing the possible causes of subsidence phenomena. According to Aslan et al. (2018), there are subsidence patterns localized on several regions over Istanbul that have vertical ground subsidence rates $5 \pm 1.2$ to $15 \pm 2.1$ $\mathrm{mm} /$ year by combining multi-track InSAR data sets (291 images in total). Moreover, Calo et al. (2015) introduces the deformation velocity map of the highly industrialized Golden Horn and surrounding areas, and the deformation rates of the European stations of recently activated tube tunnel, Marmaray. Some other studies indicate significant deformation rates focusing on the North Anatolian Fault Zone (NAFZ) (Diao et al. 2016; Walter et al. 2011) using InSAR. On the other hand, the Asian side of Istanbul has also been in a process of urbanization with huge residence and transportation projects. So that these projects have to be investigated and monitored using the tools of InSAR, to quantify and detect possible deforming areas along with the construction sites to support sustainable urbanization. Persistent Scatterer InSAR (PS-InSAR) allows researchers to detect element-based local deformations (i.e., buildings, roads), thus it could be possible to prevent catastrophic incidents using continuous monitoring models (Selvakumaran et al. 2018; Erten and Rossi 2019).

In this study, we focus on the deformation caused by the tunnel construction route passing through highly populated districts in the Anatolian part of Istanbul. We have investigated six stations of the ongoing underground construction project that have significant deformation rates detected by ground measurements. We have compared the ground observation results with the ones calculated using persistent scatters (PSs), and we also present the time series. The aims of this study are as follows: (1) detection of the deforming areas caused by the construction process on the ongoing metro line located in the Asian part of Istanbul and (2) investigation of near-real-time deformation monitoring through using Sentinel-1 data to prevent subsidence related collapses in large scale construction projects of Istanbul (Fig. 1).

\section{Motivation and the study area}

Our study area focuses on Istanbul metropolitan city, where more than fifteen million people are inhabited (Tuik.gov. tr 2019). Moreover, according to the Turkish Statistical Institute, the population of Istanbul will exceed 16 million until 2023. To overcome the needs of the people living in Istanbul, the scale and quantity of construction projects become larger. This mutual growth of the population and the constructions have various consequences such as building and road collapses, which cause human causalities (HurriyetDailynews 2017; Mimarist 2018; Evrenselnet 2018). Therefore, it becomes more crucial to precisely monitor the highly populated areas of new construction zones, as well as the routes of the new metro lines to prevent catastrophic incidents and support sustainable urbanization.
Fig. 1 a Location of the study area and $\mathbf{b}$ zoomed area of the route of the metro line with the selected stations. The background of the route is an annual velocity map of the region from PSI processing using the temporal Sentinel-1 data set
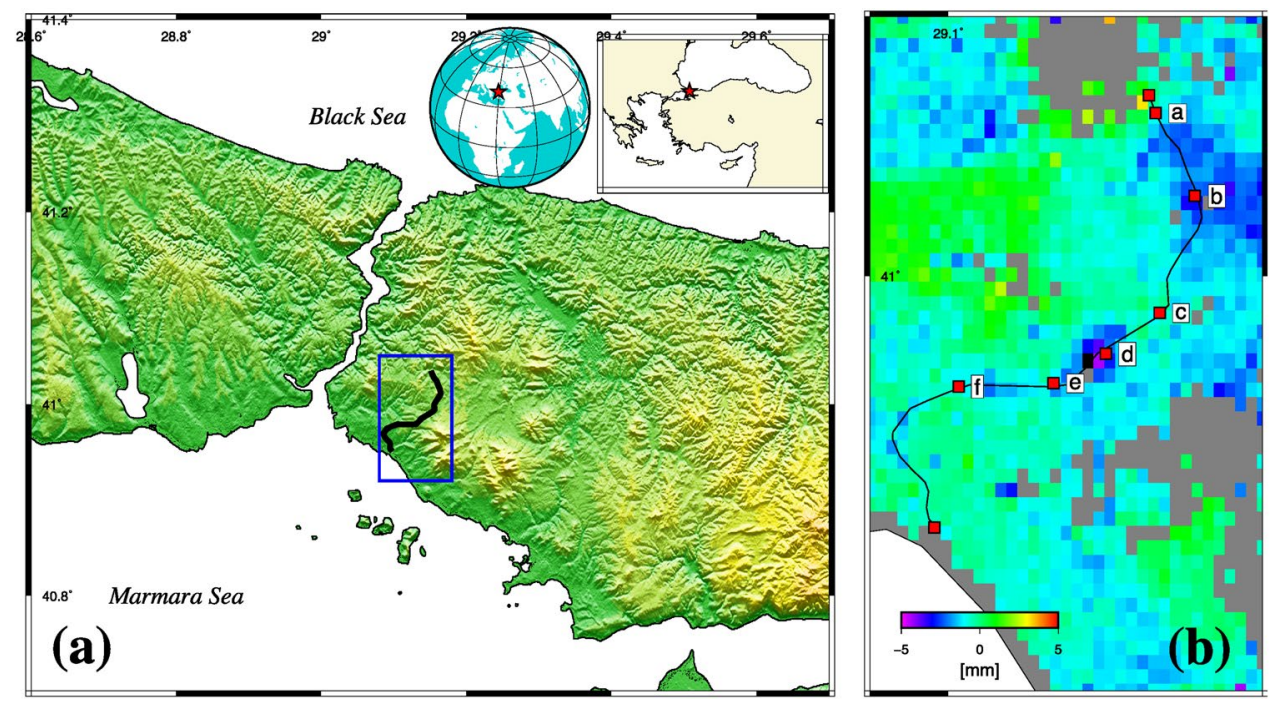
The metro line is located through north-south direction at the Anatolian part of Istanbul which is approximately $14 \mathrm{~km}$ long with 13 stations (IBB 2017). It is being constructed since 2016 and is going to be on service in 2021 with a capacity of $70 \mathrm{~K}$ passengers per hour (IBB 2015). The construction route is passing through highly populated districts of Istanbul with a total population of approximately 2 million people (Fig. 2), and also passing under two main transportation highways. Some of the stations are located close to shopping malls and industrial centers, where thousands of people visit every day. Therefore, monitoring tunneling and drilling processes have vital importance due to the increasing human traffic and population density along the construction route. For this reason, the consortium that is responsible for the construction process has a geodetic and geotechnical monitoring team on the field, and they are collecting data from the beginning of the shaft constructions. Monitoring activities are performed on potential deforming areas. Therefore, the measurements are mainly focused on the construction site and its surroundings. However, in deformation analysis, it is important to collect measurements inside the deforming area as well as the non-deforming regions before, during, and after the construction. For this reason, continuous and rapid monitoring of such huge construction projects is required to avoid the consequences of substance-related events.

In this study, we have worked on the Sentinel-1 data to determine the vertical displacements caused by the underground construction line in the Anatolian part of the city. The Sentinel-1 data is available and successfully applied to the urban monitoring studies such as railroad deformation analysis, cultural heritage, geophysical phenomena, individual buildings, and bridge deformations (Selvakumaran et al. 2018; Aslan et al. 2018; Milillo et al. 2018; Cigna et al. 2014; Aimaiti et al. 2018; Erten and Rossi 2019). We have selected six stations along the metro line that we have

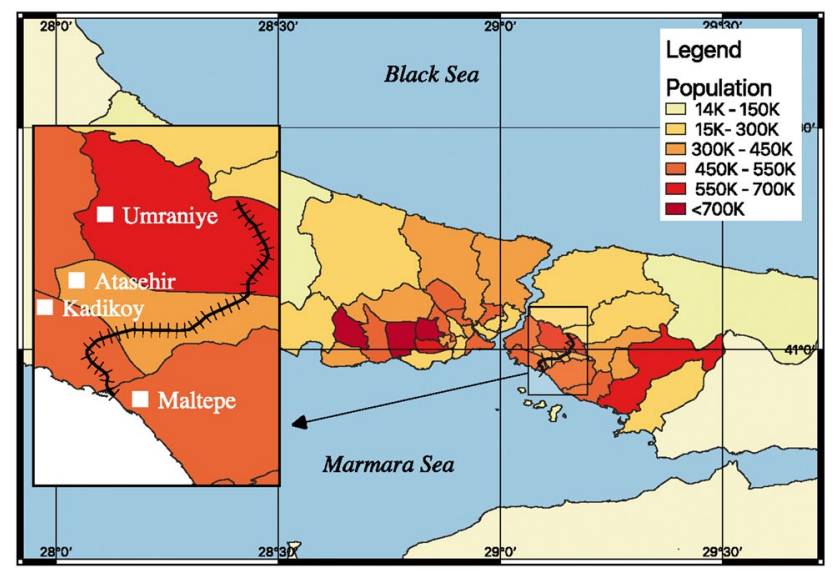

Fig. 2 Population density of the study area considered as deforming, and compared the Sentinel Line of Sight (LOS) deformation estimates with the ground-based observations ([a-f] Fig. 1). Along with the metro line construction, geometrical/trigonometrical leveling observations were performed for near-real-time deformation analysis. Finally, we have compared the vertical displacements estimated using Sentinel-1 data with the ones collected as vertical height differences at selected stations.

\section{Geological setting}

The study area is characterized by Paleozoic, including middle Devonian, Silurian, lower Ordovician, Eocene, and Quaternary deposits (Fig. 3). The study area is mainly dominated by the Paleozoic unit including especially along the route of the metro line. Post-tectonic deposits mainly observed in the middle section of the route and milestone, claystone, limestone, pebble units exist within the study area (Özgül 2012). Alluviums and man-made fills are observed along the river valleys and coastlines which are not dominant within the neighbourhood of the construction track.

\section{Data set and processing method}

The Sentinel-1 mission is conducted by the ESA within the scope of the Copernicus Programme which is a constellation of two C-Band radar satellites that provides continuous allweather imagery. The satellites have an entire word's land coverage on a bi-weekly bases (ESA 2020) and designed to support marine studies, land monitoring, and emergency services including monitoring land movements (Attema et al. 2007). The results acquired through easily accessible Sentinel-1 data support urbanization issues, deformation analysis, and contribute to the sustainability of developing cities. The Sentinel-1 satellite is continuously collecting data every 6-12 days depending on the available satellites that passing over the study area. For this purpose, a total of 123 acquisitions are taken almost every 6 days, and they have been processed. The data is freely available through Copernicus Open Access Hub (Copernicus 2018). Our process depends on all available data between March 2015 and March 2018, and the results were combined to produce time series of the designated area (Fig. 1). The data set also includes ground observations as levelling measurements in five stations which enables us to compare the results with satellite data in overlapping time intervals. PS-InSAR is a suitable interferometric image stacking technique that could be used for urban-related scenarios (Erten and Rossi 2019; Milillo et al. 2018; Calo et al. 2015). The PS-InSAR technique, which can be seen as a special class in Differential Interferometric Synthetic Aperture Radar (DInSAR), is a powerful remote 
Fig. 3 a Geological map of study area (modified after (Özgül 2012)), the metro line (red line) and investigated stations $([a-f])$. b NorthwestSoutheast profile $\left(A A^{\prime}\right)$ shown with dashed line and location of the station $[e]$ depicted with a triangle over the profile
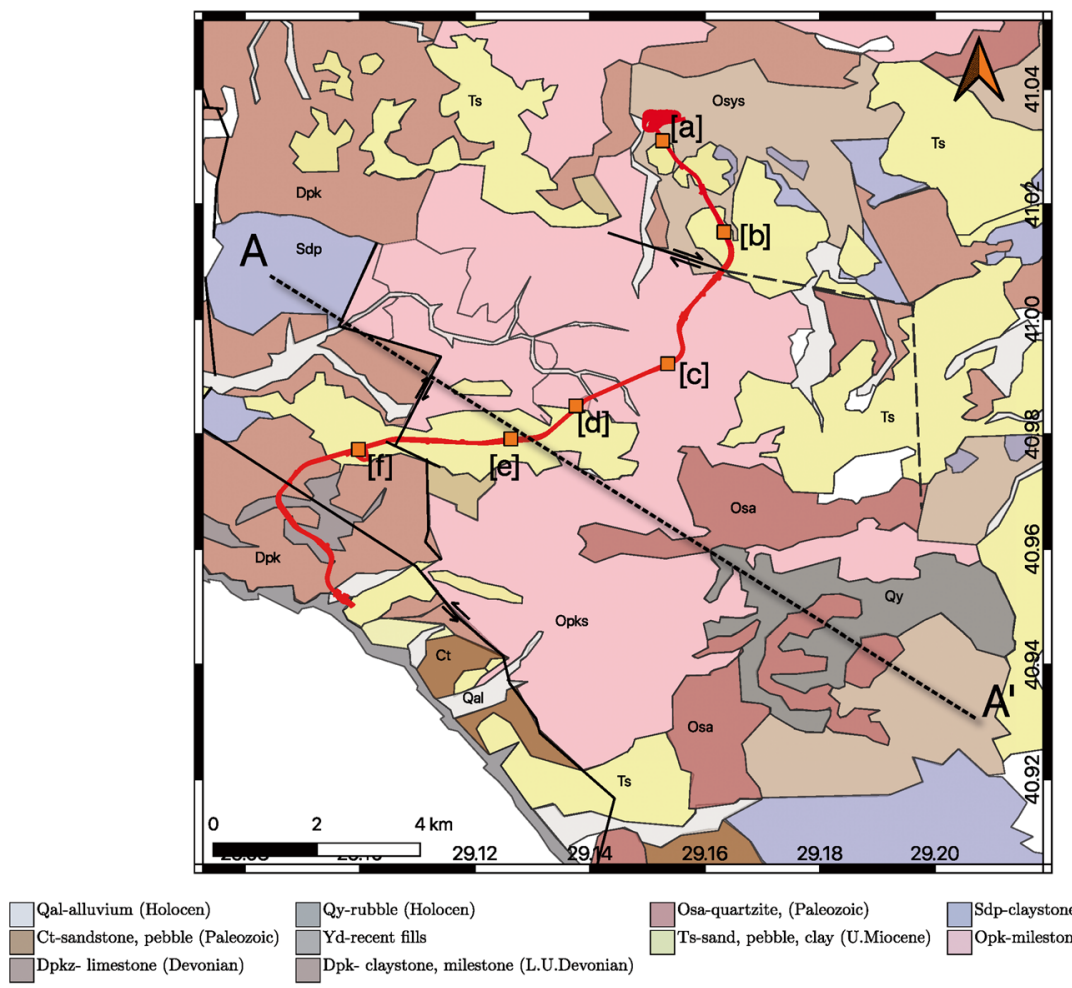

$\square$ Sdp-claystone, limestone (Paleozoic) Opk-milestone, pebble (Ordovisien)

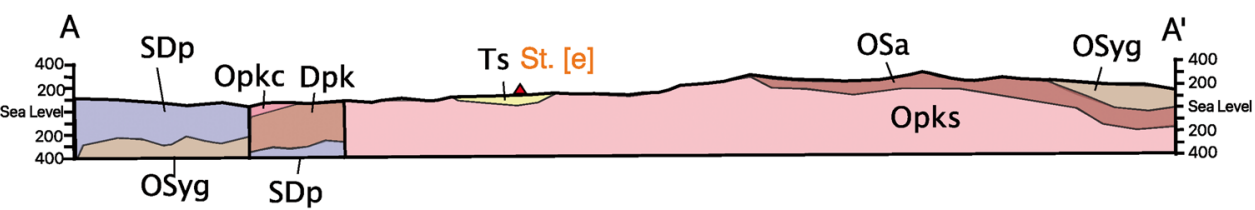

sensing technique that determines the displacements on the Earth surface (Crosetto et al. 2016).

The PSI algorithm used in this study follows four main steps which are described in detail in (Bert 2006). Firstly, differential interferograms considering a single master image are generated using the Shuttle Radar Topography Mission (SRTM) DEM as input. Then the preliminary displacement velocities are estimated independently on sub-areas of $25 \mathrm{~km}^{2}$, for which the reference point is automatically chosen to remove a phase offset from all the interferograms. Afterwards, the atmospheric phases are removed for final estimation using a low pass-filter, and a hi-pass filter in sequence. The purpose of the two filters is to account for the atmospheric spatial distribution and to consider its temporal distribution with a temporal window of 365 days, respectively. The linear displacement model is estimated, and finally, the result is geocoded. In this study, the PS-InSAR LOS deformation measurements are evaluated. A reason for which we have considered single dimension deformation is the availability of ground levelling data which provides vertical 1D height differences. To estimate the horizontal deformation rates, not available as ground reference, it would be necessary to consider ascending and descending SAR imagery.
The current study includes a stack of ascending data, and Fig. 4 shows the time-baseline plot of the interferometric processing. The master acquisition is displayed with a yellow dot and the orbital tube reaches maximum perpendicular baseline values of around $140 \mathrm{~m}$. The temporal displacement

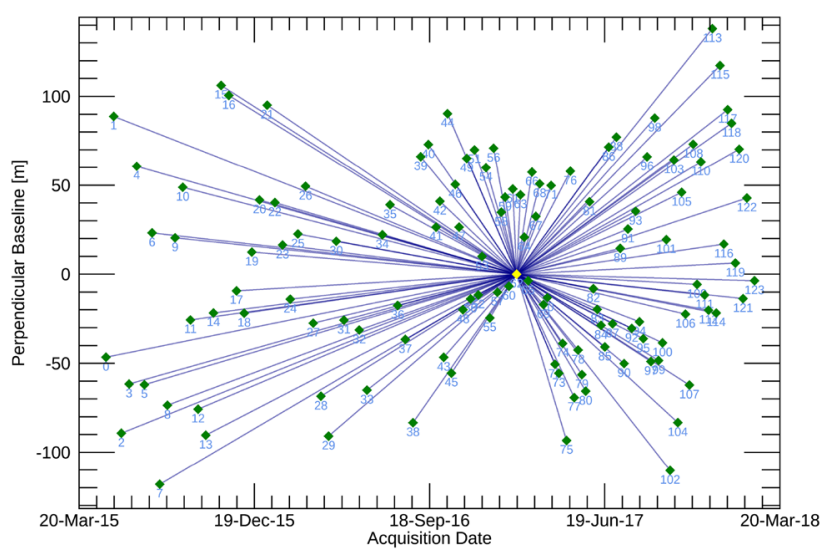

Fig. 4 Temporal (x-axis) and perpendicular (y-axis) baseline of the Sentinel-1 acquisitions. All interferograms are referred to one master (the yellow dot) image taken on 01 February 2017 
time series which are the main output of the PS-InSAR processing will be detailed in Sect. 4. An important point in the following evaulation is the displacements direction: they are calculated in the LOS of the radar sensor at a right looking direction of $34^{\circ}$.

The ground observations were performed using geometric levelling technique to determine the height differences as a function of time. The data were collected in different elevations of the shaft constructions, and stored as orthometric heights related to the national vertical datum. In this study, we have calculated the height differences according to the first epoch of observations, and plot the vertical displacements as a function of time. Figure 5 shows the temporal distribution of the observations that are used in this study.

\section{Results}

In this study, we performed an investigation along the metro line, where ground deformations were generally concentrated around the station constructions as well as the track of the metro line. We focused on six stations that we have considered as deforming, according to the time series of the Sentinel-1 LOS data and ground levelling observations. Figure $1 b$ indicates the LOS displacement velocity map over the metro line spanning March 2015 and March 2018. It can easily be seen from the velocity map that (Fig. 1b) the metro construction route has a visible subsidence pattern over a relatively stable background. Thus the trend in vertical displacement pattern of the construction route is coherent with the ground observation, as both of the results indicate subsidence at these locations (see also Fig. 6).

Figure 6 plots the information of five metro stations from north to south along the metro line with scatter points on optical imagery (left), and the time series acquired using LOS displacements with height differences are calculated through levelling (right). The station shafts are marked with orange polygons to show the surface of the construction areas. The time series have matching colors with the scatter points on the optical satellite image on the left-hand side, and the ground measurements are depicted in red triangles. The best-fitting linear model is plotted as black lines for the ground measurements, as well as for the scatter-points which have the maximum subsidence rate among neighboring points. The colored areas along the fitting line indicate prediction intervals of $95 \%$ confidence level.

The ground measurements are performed using precise geometric leveling technique, but there is no ground data available for the station $[e]$. The ground-based observations performed after clear evidence of subsidence such as cracks and local small scale collapses; therefore, the time series of such observations have a significant slope compared to the PSI time series. Moreover, through using LOS time series, it is possible to determine the areas with high displacement rates, and then ground measurements can be planned accordingly. Therefore, the ground measurements can be used as validation observations to LOS data to prevent possible collapse.

\section{Road collapse at the underground station}

In November 2018, a part of the road on Kesikkaya street collapsed at the station [a] of the metro line that might be caused by the construction-related activities (HurriyetDailynews 2017). A hole with the dimensions of $8 \mathrm{~m}$ deep and $10 \mathrm{~m}$ wide has occurred after the collapse. This specific incidence shows that there is a certain risk of collapse in rapidly developing construction projects performed in highly populated regions even if they are monitored in-situ measurements. In specific the incident occurred at the northern part of the metro line, where no ground deformations were observed according to the governmental reports. In this study we work on the data of the station [a] that was collected before the collapse, to detect the possible trends that might be interpreted as the precursor for such events. The Sentinel-1 LOS displacements within a radius of $200 \mathrm{~m}$ surrounding of the collapsed station construction are investigated and selected time series are shown in Fig. 7.

Time series indicate a clear linear trend of subsidence near the station construction in both LOS movements and the ground observations. The LOS movements reach a maximum level of around $10 \mathrm{~mm}$. Moreover, the data from ground measurements are up to $60 \mathrm{~mm}$. It should be noted that the PS measurements are in LOS geometry not in the vertical geometry. Additionally, the difference between the rates of the Sentinel data and the ground measurements
Fig. 5 Timeline of available data. Blue bar indicates Sentinel-1 data, and red bars indicate ground observations at each station

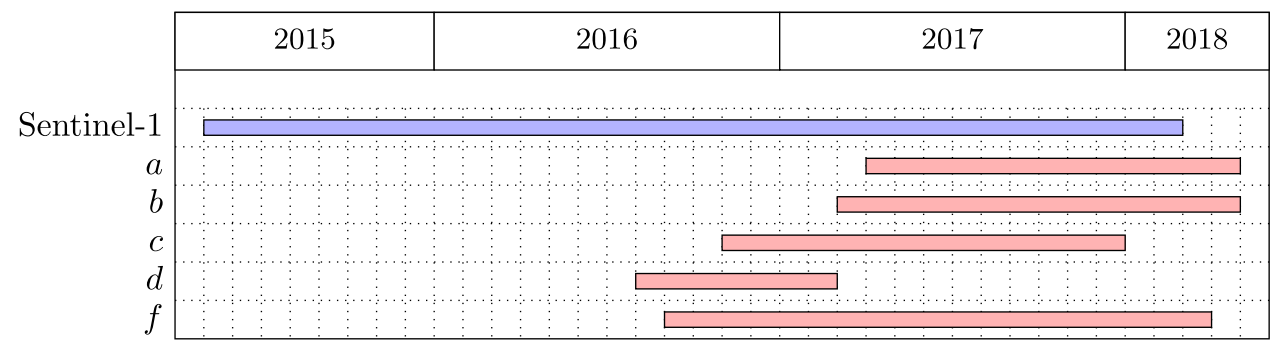



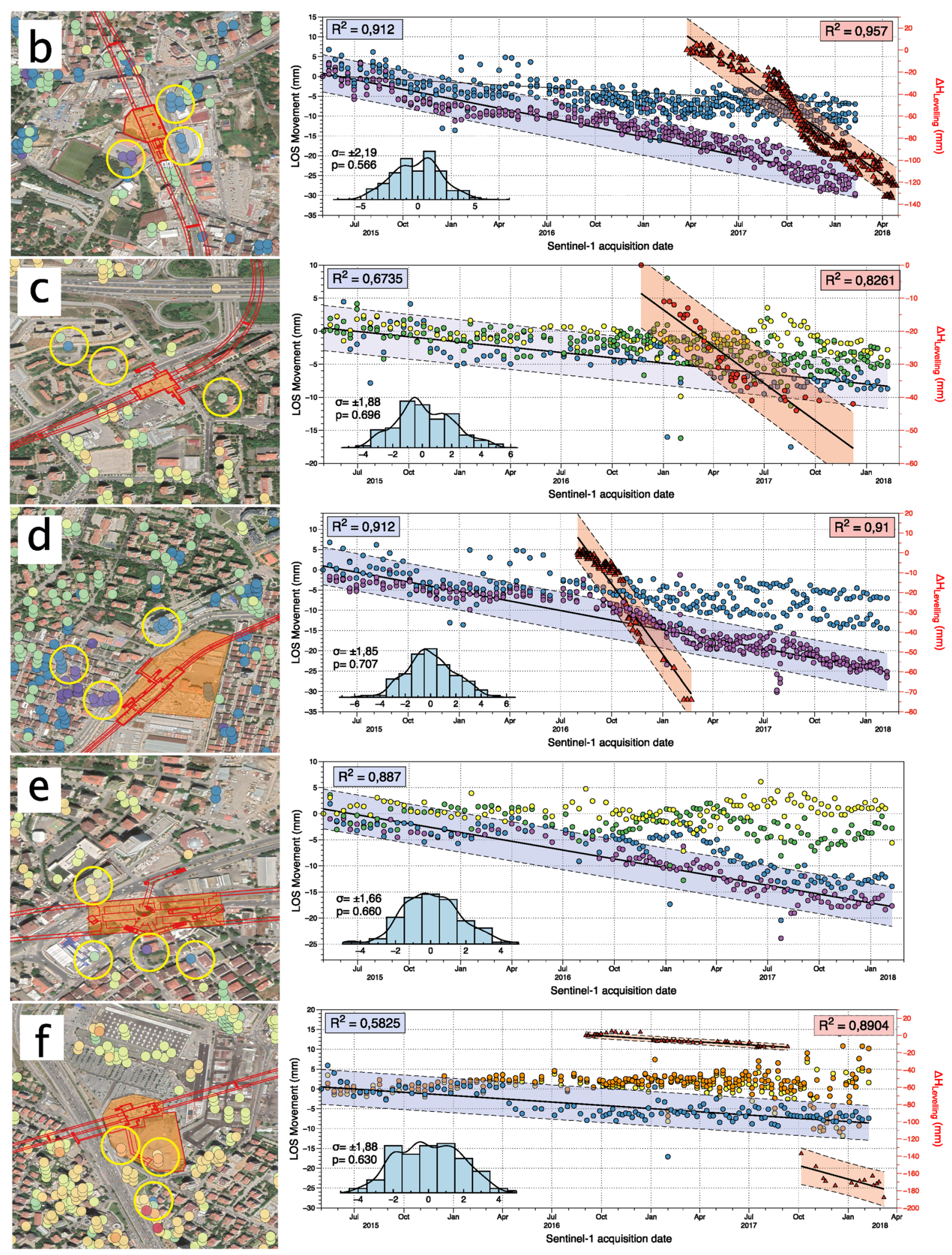

$$
\begin{aligned}
& \bigcirc(-24.0)-(-5.1) \\
& \bigcirc(-0.1)-(+0.8)
\end{aligned}
$$$$
\begin{aligned}
& (-5.1)-(-2.3) \\
& (+0.8)-(+1.9)
\end{aligned}
$$$$
\begin{aligned}
& \bigcirc(-2.3)-(-1.1) \\
& (+1.9)-(3.3)
\end{aligned}
$$$$
\bigcirc(-1.1)-(-0.1)
$$$$
(+3.3)-(+31.1) m m y r^{-1}
$$ 
4Fig. 6 Optical image and the time series of the underground stations $b-f$. Dots with different colors indicate the LOS movements showed on the image (within yellow circles), and the red triangles are the levelling observations. $R^{2}$ values are given in the upper left and right corners for LOS movement, and levelling data, respectively. The residual distributions are shown in bottom left of each sub figure with $\sigma$ and $p$-values $\left(\chi^{2}\right)$

occurred because of the difference between the location of the PS and levelling measurements. The Sentinel-1 measurements represent the surface deformation around the metro station, whereas the ground measurements are performed up to $30 \mathrm{~m}$ below the surface during the metro station construction process. The levelling data for the station $[a]$ includes two different data sets in different epochs. The first data set is performed under the surface inside the shaft construction, the second one performed on the ground surface (indicated with red and green triangles in Fig. 7, respectively). This reveals that even with its coarser resolution compared to TerraSAR-X and CosmoSky-Med, Sentinel-1 data supplies a remarkable number of PSs for the study region, which are in a reasonable match with levelling results, and they provide sufficient data to see the significant linear patterns of deformation.

At the station $[a]$, the levelling observations started and intensified just after the deformation in the surrounding buildings is visual, which was a result of subsidence. The frequency of the levelling observations is noticeable through the time series depicted in Fig. 7. The results given in this study are on selected stations of the metro line, that have significant annual velocity compared to the surrounding scatters. In the Sect. 4.2, the displacement rates are given for all stations. In the case of station $[a]$, the slope of the linear fit of time series is smaller comparing to other two stations ( $[b]$ and $[d]$, respectively). Therefore, it is apparent that if the collapse wouldn't have happened at the station $[a]$, it would have been more feasible to focus on other stations such as $[d]$ and $[b]$. However, high subsidence rates might be an indication of a catastrophic event, yet many other factors also might affect such incidents such as soil structure and building materials. Supporting ground observations, in this case, are always needed to further investigation. In this point of view, what we argue in this research that using the Sentinel data with the help of the PsInSAR technique lets us focus on the areas that need to be further investigated using ground observations. Thus, the contribution of Satellite data might be used as a supporting method to early-stage precautions for decision-makers.

\section{Investigation of station shafts along the underground route}

Times series given in Fig. 6 show a significant linear trend for LOS movements and levelling observations which demonstrate a subsidence. The $R^{2}$ values are calculated for the model that indicates a good fit for all stations. The residuals of the fit are also analysed and given in Figs. 6 and 7 along with the histograms (with $\sigma, p$ value ). According to the test results $\left(\chi^{2}\right)$, the residuals follow a Gaussian distribution. The data is also de-trended and according to auto-spectral analysis, no seasonal components are detected (Trauth and Sillmann 2012). Selected stations of the construction route have a significant rate of movements that can be distinguished from the relatively stable background scatters. There is only one collapse incident reported (station $[a]$ ) along the route of the construction. However, on remaining stations, larger displacement rate and height differences are observed than the station $[a]$. The maximum LOS displacements observed at station $[b]$ and $[d]$ are $30 \mathrm{~mm}$ and $27 \mathrm{~mm}$, respectively. The maximum annual velocities are calculated as $9.1 \mathrm{~mm} /$ year at the station $[b]$ and $8.5 \mathrm{~mm} /$ year at $[d]$. Besides, the ground observations indicate higher vertical height differences compared to the LOS displacements. The maximum height difference observed at station [f] is $188 \mathrm{~mm}$, and [b] is $134 \mathrm{~mm}$. The station [ $f$ ] shows the greatest subsidence according to the ground measurements. For the station $[f]$, the levelling measurements indicate a significant height difference between September and October 2017 at a rate of $124 \mathrm{~mm}$. The reason for this relatively rapid displacement is caused by the removal of the surface facilities that corresponds to that time interval.

In our data set, the overlap of collected levelling observations with the Sentinel data is over 93\% (Fig. 5). Therefore, we have a very good temporal correspondence in two data sets. Although the slopes of the model vary due to the reasons detailed in Sect. 5, the subsidence near stations is significant in both techniques. Furthermore, we do not expect to detect the same slope values in the time series analysis due to the differences in; observation location, precision, the density of the observations. A scenario, where the scatters and levelling points are located in the same station in both techniques would be an ideal test study to detect discrepancies in both techniques which is not the focus of this study. Thus, in this study, it can be concluded that levelling observations validate the trend of the subsidence, detected through using the PsInSAR technique.

\section{Conclusion and discussion}

In this study, we have investigated the underground metro line constructed in the Asian part of Istanbul Turkey. To do that we processed Sentinel-1 data derived around 3 years of displacements. Istanbul, which is located on a tectonically active region mainly dominated by the North Anatolian Fault Zone, is a well-studied area. Moreover, huge 

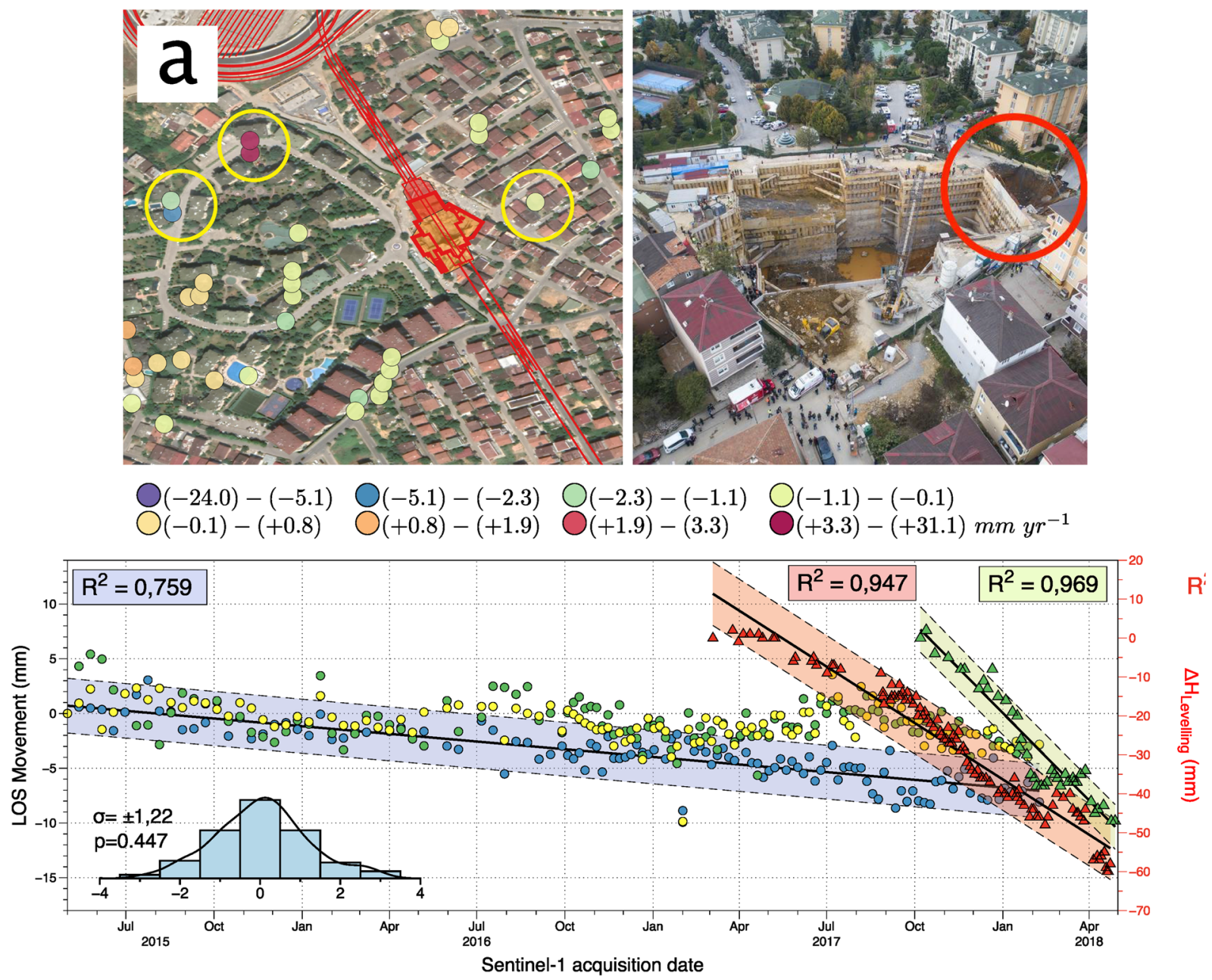

Fig. 7 Optical imagery of the Station $a$ and the time series of the surrounding area. Orange area covers the ground construction site, and the red area is the collapsed region in November 2018. Yellow circles on the satellite image indicate the plotted time series, and the red circle on the photograph shows the collapsed region. Different colors

construction projects such as the metro line studied in this paper are still not very well monitored due to the lack of ground observations such as GPS and levelling. In this study, we explore for the first time ground levelling data and the satellite-derived displacements, especially around the metro constructions. The locations where we focused on are the most rapidly deforming areas within the SAR footprint. The six selected stations that are subjected in this study (Fig. 1) have a clear subsidence trend extracted from the LOS displacements which were coherent with the ground observations. Especially at the station $[a]$ a clear trend of subsidence is observed around the construction site which has similar trend with the levelling observations.

The velocity map obtained using the PS-InSAR technique throughout the construction line of the metro line can be evaluated to detect the deforming areas. As a second stage, (yellow, green, and blue) represent scatters indicated in figure legend as annual velocity in $\mathrm{mm}$. The red and green triangles are the ground measurements performed at the construction site in two different elevations

further ground measurements can be performed in risky construction areas to validate the deformation rates. This combination of techniques enables to monitor the urban city projects in a very effective way, yet it can be used as an early warning system of possible collapses.

The vertical displacements acquired using PSI and the height differences collected using levelling technique refer to the same phenomena, namely subsidence. On the other hand, the quantity of this subsidence detected in higher rates using ground measurements are compared to the ones collected as PSI outputs. The main reason behind the difference between the LOS displacements and the ground measurements is that the LOS measurements detect the surface-tosatellite baseline differences, whereas the ground measurements are collected inside the construction area and in some cases below the surface (station $[a]$ data set shown in red 
triangles in Fig. 7). Another reason for this difference is that the maximum differential deformation rate in PSI processing is limited to $42.6 \mathrm{~mm} /$ year (Crosetto et al. 2016). Therefore, while comparing ground and scatter plots the trends in the time series should be considered rather than the quantity of displacement rates.

Finally, the investigation of possible deforming areas of the underground metro line has vital importance due to the residents of the area and the ongoing mobility of the high population near the construction route. Moreover, a road collapse that occurred next to the shaft construction of station $[a]$, indicates a visible linear trend in LOS time series and significant vertical deformation rates gathered from levelling measurements. Besides, maximum and minimum displacements calculated using PSI technique are $12 \mathrm{~mm}$ and $92 \mathrm{~mm}$, respectively. Ground measurements have been performed on five construction sites and the vertical deformation rates are measured between 44 and $188 \mathrm{~mm}$.

PSI technique is a valuable tool for urban monitoring and tunneling deformations in terms of proving freely available alternative data in large scale studies. This study focused on a recently active underground construction to test the performance and usability of the PSI technique with the combination of ground measurements in near real-time. PSInSAR data is suitable to detect deformations for large areas like cities and can support further analysis of local deformations using ground observations. Therefore, satellite data can be used as an early warning system and they can support the decision-makers of highly populated cities.

We claim to use Sentinel results not only in small areas such as a metro line but also to practice it for a whole district or a city as an emergency plan to prevent collapses.

Funding Open Access funding enabled and organized by Projekt DEAL.

Open Access This article is licensed under a Creative Commons Attribution 4.0 International License, which permits use, sharing, adaptation, distribution and reproduction in any medium or format, as long as you give appropriate credit to the original author(s) and the source, provide a link to the Creative Commons licence, and indicate if changes were made. The images or other third party material in this article are included in the article's Creative Commons licence, unless indicated otherwise in a credit line to the material. If material is not included in the article's Creative Commons licence and your intended use is not permitted by statutory regulation or exceeds the permitted use, you will need to obtain permission directly from the copyright holder. To view a copy of this licence, visit http://creativecommons.org/licenses/by/4.0/.

\section{References}

Aimaiti Y, Yamazaki F, Liu W (2018) Multi-sensor insar analysis of progressive land subsidence over the coastal city of Urayasu, Japan. Remote Sens 10(8):1304
Aslan G, Cakir Z, Ergintav S, Lasserre C, Renard F (2018) Analysis of secular ground motions in Istanbul from a long-term InSAR time-series (1992-2017). Remote Sens 10(3):408. https://doi.org/ $10.3390 /$ rs 10030408

Attema E, Bargellini P, Edwards P, Levrini G, Lokas S, Moeller L, Rosich-Tell B, Secchi P, Torres R, Davidson M et al (2007) Sentinel-1-the radar mission for gmes operational land and sea services. ESABu 131:10-17

Bert MK (2006) Radar interferometry: persistent scatterers technique. Springer, The Netherlands

Calo F, Abdikan S, Görüm T, Pepe A, Kilic H, Balik Sanli F (2015) The space-borne SBAS-DInSAR technique as a supporting tool for sustainable urban policies: the case of Istanbul Megacity, Turkey. Remote Sens 7(12):519-536

Cigna F, Lasaponara R, Masini N, Milillo P, Tapete D (2014) Persistent scatterer interferometry processing of COSMO-SkyMed StripMap HIMAGE time series to depict deformation of the historic centre of Rome, Italy. Remote Sens 6(12):12593-12618

Copernicus (2018) Open access hub. https://scihub.copernicus.eu, Accessed 29 Sept 2020

Crosetto M, Monserrat O, Cuevas-González M, Devanthéry N, Crippa B (2016) Persistent scatterer interferometry: a review. ISPRS J Photogramm Remote Sens 115:78-89

Diao F, Walter TR, Minati F, Wang R, Costantini M, Ergintav S, Xiong X, Prats-Iraola P (2016) Secondary fault activity of the north anatolian fault near avcilar, southwest of istanbul: evidence from SAR interferometry observations. Remote Sens. https://doi.org/10.3390/rs8100846

Dirscherl M, Rossi C (2018) Geomorphometric analysis of the 2014-2015 Barbarbunga volcanic eruption, Iceland. Remote Sens Environ 204:244-259

Dogan E, Stupar A (2017) The limits of growth: a case study of three mega-projects in Istanbul. Cities 60:281-288

Erten E (2013) Glacier velocity estimation by means of a polarimetric similarity measure. IEEE Trans Geosci Remote Sens 51(6):3319-3327

Erten E, Rossi C (2019) The worsening impacts of land reclamation assessed with Sentinel-1: the Rize (Turkey) test case. Int J Appl Earth Obs Geoinf 74:57-64

Erten E, Reigber A, Hellwich O (2010) Generation of threedimensional deformation maps from InSAR data using spectral diversity techniques. ISPRS J Photogramm Remote Sens 65(4):388-394

ESA (2020) esa sentinel online. https://sentinel.esa.int. Accessed 29 Sep 2020

Evrenselnet (2018) Building evacuated for the collapse risk. http://bit. ly/basin-sit. Accessed 29 Sep 2020

HurriyetDailynews (2017) Hurriyet dailiy news, two die after road collapses in Istanbul's Ümraniye district. http://bit.ly/road-collapse. Accessed 29 Sep 2020

IBB (2015) Munucipility of Istanbul, Bostanci Dudullu metro line. http://www.dudullubostancimetro.com/haberler. Accessed 29 Sep 2020

IBB (2017) Manicipulaty of istanbul press bulletin. https://www.ibb. istanbul/News/Detail/33734. Accessed 29 Sep 2020

Imamoglu M, Kahraman F, Cakir Z, Sanli FB (2019) Ground deformation analysis of Bolvadin (W. Turkey) by means of multi-temporal InSAR techniques and Sentinel-1 data. Remote Sens. https://doi. org/10.3390/rs11091069

Keyder Ç (2010) Istanbul into the twenty-first century. In: Orienting Istanbul, Routledge, pp 41-50

Milillo P, Giardina G, DeJong M, Perissin D, Milillo G (2018) Multitemporal InSAR structural damage assessment: the London crossrail case study. Remote Sens 10(2):287

Mimarist (2018) Press release of chamber of architects of Turkey. http://bit.ly/kartal-collapse. Accessed 29 Sep 2020 
Øverli Eriksen H, Lauknes TR, Larsen Y, Corner GD, Bergh SG, Dehls J, Kierulf HP (2017) Visualizing and interpreting surface displacement patterns on unstable slopes using multi-geometry satellite SAR interferometry (2D InSAR). Remote Sens Environ 191:297-312. https://doi.org/10.1016/j.rse.2016.12.024

Özgül N (2012) Stratigraphy and some structural features of the Istanbul palaeozoic. Turkish J Earth Sci 21(6):817-866

PMISPA (2019) Turkey's 'mega projects' propel the country towards 2023 targets. The Republic of Turkey Prime Ministry Investment Support and Promotion Agency of Turkey. http://bit.ly/invest-TR. Accessed 29 Sep 2020

Selvakumaran S, Plank S, Geiß C, Rossi C, Middleton C (2018) Remote monitoring to predict bridge scour failure using interferometric Synthetic Aperture Radar (InSAR) stacking techniques. Int J Appl Earth Obs Geoinf 73:463-470. https://doi.org/10.1016/j. jag.2018.07.004

Sonmez M (2017) Economy politics of mega projects in Istanbul. Mimarist J Chamber Arch Turkey 17(58):32-36

Tomás R, Romero R, Mulas J, Marturià JJ, Mallorquí JJ, LopezSanchez JM, Herrera G, Gutiérrez F, González PJ, Fernández $\mathrm{J}$ et al (2014) Radar interferometry techniques for the study of ground subsidence phenomena: a review of practical issues through cases in Spain. Environ Earth Sci 71(1):163-181

Trauth M, Sillmann E (2012) MATLAB $®$ and design recipes for Earth sciences: How to collect, process and present geoscientific information. Springer Science \& Business Media

Tuikgovtr (2019) Turkish statistical institute, population projections. http://bit.ly/tr-population. Accessed 29 Sep 2020

Walter TR, Manzo M, Manconi A, Solaro G, Lanari R, Motagh M, Woith H, Parolai S, Shirzaei M, Zschau J, Baris S, Ansal A (2011) Satellite monitoring of hazards: a focus on Istanbul, Turkey. Eos Trans Am Geophys Union 91(36):313-314. https://doi.org/10. 1029/2010EO360001

Yapicı M (2019) Urban transformation in Istanbul. In: Authoritarianism and Resistance in Turkey, Springer, pp 63-71

Publisher's Note Springer Nature remains neutral with regard to jurisdictional claims in published maps and institutional affiliations. 